\title{
Human Myeloid-Derived suppressor cells in solid organ transplantation
}

\author{
María Iglesias Escudero ${ }^{1}$, David San Segundo ${ }^{2}$ and Marcos López-Hoyos ${ }^{2,3 *}$ \\ ${ }^{1}$ Autoimmunity and Transplantation Group, IDIVAL, Santander, Spain \\ ${ }^{2}$ Servicio de Inmunología, Hospital Universitario Marqués de Valdecilla-IDIVAL, Santander, Spain \\ ${ }^{3}$ Molecular Biology Department, University of Cantabria, Santander, Spain
}

\begin{abstract}
The balance between effector and regulatory immune cells needs a very exquisite balance in the context of solid organ transplantation to avoid the rejection of the organ while maintaining the more immune competence as possible. In the last two decades the role of regulatory immune cells has been extensively studied, mainly with regulatory $\mathrm{T}$ cells (Tregs), and in the last years another subset of regulatory cells, named myeloid derived suppressor cells (MDSC), has gained importance. These cells have different mechanisms of action and some of them are differentially regulated in a number of immune-mediated processes. Thus, MDSC, which play important roles in tolerance of experimental models of solid organ transplantation, have been proposed as biomarkers of the degree of immunosuppression and risk of rejection. Besides, they are also thought as therapeutic approach for the establishment of tolerance in human transplantation.
\end{abstract}

\section{Introduction}

Solid organ transplantation is a primary therapy in patients with end-stage disease. Throughout the years immunosuppressive protocols have clearly reduced the incidence of acute rejection, but current pharmacological protocols still result in undesirable side effects, such as infection and cancer among others, what results in a moderate long-term allograft survival [1,2]. As a consequence, the main goals in transplantation are to predict the risk of developing rejection and to find alternative tolerance approaches to allow immunosuppression withdrawal in order to minimize the adverse effects that have deleterious effects on long term graft survival. In this regard, myeloid cells, which are involved both in non-specific reactions and donor-specific adaptive responses during allograft rejection, play a main role starting and controlling immune responses. Under certain circumstances, they contribute to the inflammatory process, expanding disease pathology. However, myeloid cells with regulatory properties can protect the host from uncontrolled inflammation. These cells, known as myeloid regulatory cells (MRCs), have been described within all the major myeloid cell lineages. Among them, myeloid-derived suppressor cells (MDSCs) have been described as a heterogeneous group of myeloid cells known to accumulate under chronic pathological conditions [3]. As a reflection of their biology, these cells had been called "immature myeloid cells" or "myeloid suppressor cells" (MSC) but as neither term was considered as accurate, Gabrilovich DI, et al. [4] proposed the term "myeloid -derived suppressor cells' considering this term closer to reflect their origin and function. The first observations of suppressive myeloid cells were described more than 20 years ago in patients with cancer [5-7]. However, their functional importance in the immune system has only recently been appreciated due to the evidence that has demonstrated their contribution to the negative regulation of immune responses in cancer and other clinical settings, such as organ transplantation, infection and autoimmune diseases [3,8-12]. Initially MDSC have been described as immature cells that expand in the bone marrow in response to chronic inflammatory signals but evidence support in certain circumstances MDSC may represent monocytes and neutrophils that have been activated into immunosuppressive populations [13].

In transplantation the MDSCs are able to suppress adaptive and innate immune responses and they have been suggested as potential biomarkers for allograft tolerance as they can play a main role in the balance between graft acceptance and rejection $[14,15]$. The MDSCs were first described in mice as $\mathrm{CD} 11 \mathrm{~b}^{+} \mathrm{Gr} 1^{+}$cells and experimental transplant models demonstrated they have an important role in the induction of tolerance $[15,16]$. As most of the published studies were performed in animal models, there is a paucity of data addressing MDSC features and their role in human transplantation. Human MDSCs in peripheral blood are classified in three main subsets: monocytic-MDSC (Mo-MDSCs: CD33 ${ }^{+} \mathrm{CD}_{11 b^{+} \text {CD14 }}{ }^{+}$HLA-DR-/ low), polymorphonuclear-MDSC (PMN-MDSCs:CD11b ${ }^{+}$CD14 $\mathrm{CD}^{+} 5^{+}$HLA-DR or $\left.\mathrm{CD}^{-} 1 \mathrm{~b}^{+} \mathrm{CD} 14+\mathrm{CD}^{-} 6 \mathrm{~b}^{+}\right)[17]$ and a population lacking both differentiation surface markers classified as early- stage MDSC (e-MDSCs: CD33+ CD15 CD14-HLA-DR) [17]. CD33 marker can be used instead of CD11b since very few $\mathrm{CD} 15^{+}$cells are CD11b. While Mo-MDSC are $\mathrm{CD}_{3} 3^{+}, \mathrm{PMN}-\mathrm{MDSC}$ are $\mathrm{CD}^{3}{ }^{\mathrm{dim}}$ [18]. The features and clinical relevance of e-MDSC are not well stablished but limited suppression of $\mathrm{T}$ cell proliferation and cytokine expression was found by some authors [19]. Other suggested makers in human MDSCs include high levels of CD66b and low levels of CD62L and CD16, vascular endothelial growth factor receptor 1 (VEGFR1) (Flt1) [20] and expression of CD124 [21]. Initially the term 'granulocytic MDSC' was used to describe PMN-MDSC [22,23] but since PMN-

${ }^{\star}$ Correspondence to: Marcos López Hoyos, Autoimmunity and Transplantation Group, IDIVAL, Santander, Spain, E-mail: marcos.lopez@scsalud.es

Received: January 15, 2021; Accepted: January 22, 2021; Published: January 25, 2021 
MDSC are phenotypically distinct from steady-state neutrophils lately $\mathrm{V}$. Bronte, et al. proposed the term PMN as more accurate to define this subset [17]. Because these markers are not exclusively expressed by MDSCs, these regulatory cell subsets are best defined by their capacity to suppress T cell proliferation [24], which is associated with their ability to induce $\mathrm{T}$ cell apoptosis [25] and expand Treg cells [26] (Figure 1). Moreover, the interaction between MDSC and other immune cells has been described in recent years [27-30]. It is important to remark that assays of human MDSC function are difficult to implement due to their technical complexity and high variability. At the present time, the technique allowing for separation of neutrophils from PMN-MDSC is Ficoll gradient regularly used for the isolation of mononuclear cells. Low- density fraction contains PMN-MDSC and activated neutrophils. Therefore, $\mathrm{CD} 11 \mathrm{~b}^{+} \mathrm{CD} 14 \mathrm{CD} 15^{+} / \mathrm{CD}^{-} 6^{+}$cells in low-density fraction contain both PMN-MDSC and neutrophils [17]. Hence, there is a need for reliable surrogate markers of human MDSC function as gating criteria cannot discriminate monocytes from MoMDSCs and neutrophils from PMN-MDSC since at present there are no combinations of markers exclusive to MDSC. Human MDSCs exert their $\mathrm{T}$ cell suppressive actions through a wide variety of mechanisms, including production of anti-inflammatory cytokines and upregulation of immune- regulatory molecules, including arginase 1 (Arg1) and indoleamine 2,3-dioxygenase (IDO) [31,32] (Figure 1). Conventional phenotyping of human Mo-MDSC subsets mainly relies upon HLA-DR expression; however, it is unclear to what extent HLA-DR expression is influenced by standard immunosuppression, especially glucocorticoids. The release of neutrophils from the bone marrow in response to glucocorticoids is well established [33] and it has been reported that glucocorticoids can induce antiinflammatory monocytes resembling MDSC [34,35]. In previous experiments from our group (data not published) we observed a dose-dependent reduction in HLA-DR expression levels in monocytes

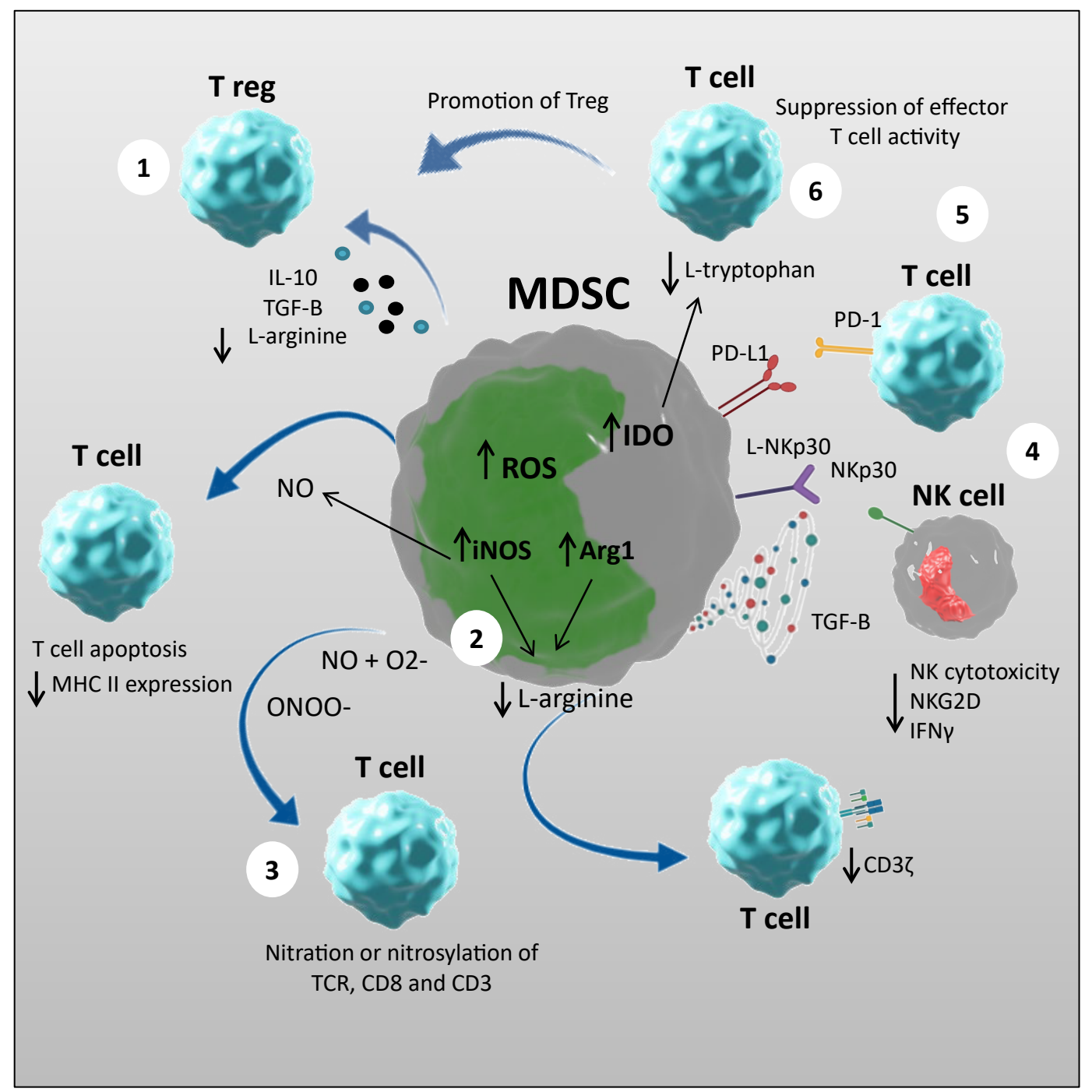

Figure 1. Mechanisms of MDSC suppressive activity

MDSC exert their suppressive function through a variety of mechanisms: (1) secretion of anti--inflammatory mediators, such as IL--10 and TGF-- $\beta$ that promote induction of T--regulatory cells; (2) increased arginase and iNOS: the increased activity of arginase leads to enhanced L--arginine catabolism. The lack of L--arginine inhibits T--cell proliferation through different mechanisms, including decreasing their CD3 $\zeta$ expression; on the other hand iNOS generates NO which suppresses T--cell function inhibiting, MHC class II expression and inducing T--cell apoptosis; (3) increased production of ROS generates peroxynitrite which induces the nitration and nitrosylation of the amino acids and mediate MDSC suppression of T--cell function; (4) MDSCs can inhibit NK cell function by interacting with the NKp30 receptor; (5) inducing increased PD--1 expression; and (6) increased IDO activity which catabolizes tryptophan and limits T cell proliferation. 
after dexamethasone exposure, monocytes were phenotypically indistinguishable from Mo-MDSC. In the critical illness context, Le Tulzo, et al. studied 48 septic patients and found an association between high levels of circulating cortisol and reductions in monocyte HLA-DR expression on day 6 of illness [36]. The authors then demonstrated in vitro that dexamethasone caused a down-regulation of a key transcription factor for HLA-DR in normal monocytes. They suggest that glucocorticoid action may represent another mechanism for the development of innate immune dysfunction. Similarly, Volk, et al. demonstrated that the administration of methylprednisolone in the setting of cardiopulmonary bypass resulted in an exacerbation of innate immunosuppression over that obtained with bypass alone [37]. An important goal for future studies is to define cell-surface markers and gating strategies that uniquely identify the different populations of MDSC. On the other hand, a major challenge in immune monitoring of transplant recipients is distinguishing between changes in biomarkers reflective of underlying alloimmune responses versus changes related to immunosuppressive therapy.

\section{Kidney Transplantation}

In kidney transplant models Dugast, et al. reported the role of MDSC in kidney transplant recipient rats [38]. In this model, MDSC in the recipient allograft were described for the first time in organ transplantation and their suppressive mechanism of tolerance was in part mediated by iNOS. In concordance, the role of NO (nitric oxide) in MDSC mediated suppression was first described by Mazzoni [39]. Another report from Vanhove's laboratory reported that secretion of CCL5 by MDSC was responsible for the accumulation of Treg into tolerized kidney allografts [40]. In subsequent studies the results indicate that a gradient of CCL5 might contribute to the intra graft localization of Treg in tolerant recipients controlled by MDSC [41]. In human kidney transplantation Luan, et al. found that the overall MDSC frequencies were elevated at 3, 6 and 12 months post-transplant [42]. Utrero-Rico, et al., observed Mo-MDSC cells counts rapidly increase after kidney transplantation and remain high one year after transplantation [43]. Hock et al. showed that renal transplant recipients (RTR) had elevated frequencies of circulating MDSC [8], but they further found MDSC numbers had returned to normal levels 12 months post-transplantation [44]. However, in their previous study of RTRs with longer term transplants elevated MDSC numbers were detected in the majority of patients, suggesting that MDSC expand in the long-term, as the graft acceptance progresses. In a previous report from our group we evaluated the phenotype and function of different MDSCs subsets in 38 kidney transplant recipients (KTR) at different time-points and our data indicated that Mo-MDSC increase in KTR at 6 months and 12 months post-transplantation [45]. Moreover, the MDSCs were shown to expand early after transplantation, independently of using basiliximab or thymoglobulin during induction [44] and almost tolerant kidney transplant recipients (ATKTRs) had significantly higher levels of monocytic MDSCs and CD4+CD25+FoxP3+ Tregs than short-term graft survival kidney transplant recipients and healthy donors [46].

These observational studies suggest that MDSC numbers increase rapidly after transplantation and peak following immunosuppressive therapy. Moreover, analysis of the changes in MDSCs obtained from donors, provided strong evidence that the changes occurring in RTRs were likely due to the immunosuppressive regimens rather than the acute inflammation from surgery itself [44]. Although Mo-MDSC phenotype seems to be influenced by standard immunosuppression, especially glucocorticoids, whether MDSC subsets are differentially regulated by local conditions or treatments require further investigations.
Studies developed in mice suggest that MDSCs have an important role to induce $\mathrm{T}$ regulatory cells (Treg) after transplantation [16,47], but their role in human transplantation is under investigation. In KTR, Luan, et al. observed that $\mathrm{CD}_{3} 3^{+} \mathrm{CD} 11 \mathrm{~b}^{+} \mathrm{HLA}-\mathrm{DR}^{-}$MDSC are capable of expanding Treg, and they correlate with Treg increases in vivo (42). Consistent with this view, Meng, et al. [48] found that MDSCs isolated from transplant recipients were also able to expand regulatory $\mathrm{T}$ cells and were associated with longer allograft survival, and we also reported an increase in Treg expansion after Mo-MDSC coculture [45]. Further, the Mo-MDSC levels correlated positively with the survival rates, estimated glomerular filtration rates (eGFRs) of grafts, and the levels of CD4+CD25+FoxP3+ Treg in ATKTRs [46]. In two cohorts of patients with acute rejection the mRNA levels of S100A8 and S100A9 in biopsies predicted improved graft outcome. Expression of both proteins correlated with MDSC markers in PBMC and renal biopsies and higher expression of immune regulatory molecules [49]. Due to the lack of unique phenotypic markers functional studies have to be performed to identify MDSC subsets [24]. Murphy, et al. evaluated the capacity of blood derived $\mathrm{CD}_{11} \mathrm{~b}^{+} \mathrm{CD} 33^{+} \mathrm{HLADR}^{-}$MDSC from human KTRs to suppress $\mathrm{CD} 4+\mathrm{T}$ cells proliferation in vitro [42] demonstrating that

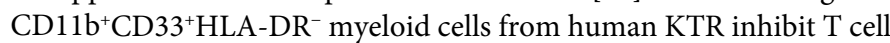
proliferation, but no inhibition was found when $\mathrm{CD} 11 \mathrm{~b}^{+} \mathrm{CD} 33^{+} \mathrm{HLA}-$ $\mathrm{DR}^{-}$cells were obtained from healthy donors [42]. Moreover, we observed that Mo-MDSC from KTR under tacrolimus treatment had increased suppressive activity compared to rapamycin [45] and we attribute loss of suppressive function to diminished IDO expression in rapamycin-exposed Mo-MDSC. However, another study addressing the murine MDSC response to acute kidney injury demonstrated that MDSC reduced the injury, and the effect was potentiated by MDSC induction and enhancement of the immunosuppressive activity promoted by mTOR [50]. More recently, a previously unrecognized mechanistic pathway associated with organ rejection identifies the expression of mTOR by graft infiltrating macrophages at the center of epigenetic and metabolic changes that correlate with graft loss [51]. This novel functional mechanism has been termed "trained immunity" [52]. Therefore, it seems that, while mTOR inhibition may prevent trained immunity and inflammatory pathways in myeloid cells [53,54], it may also interfere with tolerogenic programming and the ability of myeloid cells to expand Treg and suppress T-cellmediated immune responses. This dual effect of mTOR inhibition in vivo is likely to determine the outcome of the transplanted organ.

\section{Liver Transplantation}

In the 1990s, Settmacher, et al. described an association between aggressive calcineurin inhibition and a reduction HLA-DR expression in monocytes in the setting of induction therapy in adults following liver transplantation [55]: among 91 patients, those whose monocyte HLA-DR expression dropped below 30\% experienced increased rates of bacteremia, viremia, and fungemia compared to those whose HLADR levels remained $>30 \%$. In the same manner, Haveman JW, et al. monitored 20 liver transplantation recipients during the first month after transplantation and measured the expression of HLA-DR in monocytes. Seven out of 20 patients developed sepsis after a median of 15 days post-transplantation and HLA-DR expression was significantly lower in these patients. The expression of HLA-DR in monocytes remained low before onset of sepsis. On day 7 after transplantation, HLADR expression on $50 \%$ or less of monocytes had a positive predictive value for sepsis of $71 \%$, whereas the negative predictive value was $85 \%$. Furthermore, patients who received significantly more prednisolone 
developed sepsis. The authors conclude that low HLA-DR expression on monocytes is a marker for a high risk of subsequent sepsis in liver transplantation patients and this high risk may be related to the dose of prednisolone [56]. It is known that under inflammation and fibrosis, MDSC are induced in the liver due to the local conditions [57]. MDSC are recruited in the liver and they differenciate by mechanisms that depend on contact between several cell types and on soluble mediators. For example, hepatic stellate cells promote MDSCs in mice and humans and mesenchymal stromal cells in human [58]. Bernsmeier, et al. reported that immunosuppressive CD14 ${ }^{+}$HLA-DR-Mo-MDSCs, are expanded in patients with acute-on- chronic liver failure (ACLF) and TLR-3 agonists reversed Mo-MDSC expansion [59]. In a murine model, rapamycin induced the recruitment of MDSC and protected against immunological hepatic injury. Downregulating the mTOR activity in MDSCs induced iNOS and NO, and the pharmacological inhibition of iNOS completely eliminated the recruitment of MDSCs [60]. In another model of allogeneic liver transplantation, the authors observed an increase of regulatory $\mathrm{T}$ cell phenotypes and accumulation of MDSC in spleen [61].

\section{Lung Transplantation}

Hoffman, et al. monitored HLA-DR expression weekly after transplantation in 13 pediatric lung transplant recipients (LRT) [62]. Six out of seven patients who developed post-transplant pneumonia demonstrated lack of monocyte HLA-DR expression within the first two weeks of monitoring and those who developed pneumonia had lower monocyte HLA-DR expression over the four-week study period than those who remained infection-free. The authors propose that monitoring HLA-DR expression in monocytes may be useful to identify risk of infection and stratifying patients into higher and lower risk groups. Alingrin, et al. assessed the influence of early post-operative sepsis on $\mathrm{T}$ cell and monocyte reconstitution in anti- thymocyte globulin (ATG)-treated lung transplant recipients. Peripheral blood T-lymphocytes counts and monocyte HLA-DR (mHLA-DR) expression within 60 days post-transplant were analyzed. The authors found that sepsis is negatively correlated with the HLA-DR expression in monocytes [63]. These findings taken together highlight the importance of immunomonitoring after lung transplantation. Deshane, et al. found high numbers of CD $11 \mathrm{~b}^{+} \mathrm{CD} 14^{+} \mathrm{CD} 16^{-} \mathrm{HLA}^{-\mathrm{DR}^{-}} \mathrm{NO}-$ producing myeloid derived regulatory cells, in the airways of patients with asthma but not in patients with chronic obstructive pulmonary disease (COPD) or in healthy control subjects [64]. On the other hand Scrimini, et al. observed elevated levels of circulating-lineage HLA-DR $\mathrm{CD}_{3}{ }^{+} \mathrm{CD} 11 \mathrm{~b}^{+} \mathrm{MDSC}$ in patients with COPD [65]. Other researchers demonstrated that CCR2 ${ }^{+}$Mo-MDSCs inhibit collagen degradation and promote lung fibrosis by producing transforming growth factor- $\beta 1$ (TGF- $\beta 1$ ) [66]. The number of circulating activated MDSCs was found to be significantly increased in patients with pulmonary hypertension $(\mathrm{PH})$ compared to control subjects, and was correlated with an increase in mean pulmonary artery pressure [67]. Sharma, et al. described the association of distinct MDSC sub-populations with the lung microbiome in LTRs. Their results suggested a functional link between the local microbiome and MDSC phenotype, which may play a role in the pathogenesis of BOS [68].

One from our group (unpublished) analyzed MDSC frequencies in 82 LTR were analyzed during the first year after transplantation. Percentages of total MDSC were increased in LTR 3 months after transplantation up to a year. When we studied the effect of transplantation on MDSC subsets in our cohort, Mo-MDSC percentages increased promptly after transplantation and decreased gradually during follow up. On the contrary, PMN-MDSC percentages decreased in the short term after transplantation, and increased during follow up although no changes compared to pre-transplant levels were observed. Compared to pre-transplant levels, e-MDSC percentages were significantly increased at 7 days, 21days and 360 days. We obtained similar results when we calculated MDSC absolute numbers. In previous experiments we observed a dose-dependent reduction in HLA-DR expression levels in monocytes after dexamethasone exposition, then monocytes were phenotypically indistinguishable from Mo-MDSC. On concordance with these results, some studies previously published $[33,37,56]$ point corticosteroids are modulating MDSC levels then we hypothesize that corticosteroids are increasing Mo-MDSC populations in peripheral blood immediately after transplantation. We observed (unpublished data) the suppressive capacity of MDSC from Tacrolimus treated LTR is increased compared to the suppressive results when $\mathrm{CD} 14^{+} \mathrm{CD} 11 \mathrm{~b}^{+} \mathrm{CD} 33^{+} \mathrm{HLA}-\mathrm{DR} \mathrm{R}^{-}$cells were obtained from healthy donors. Heigl, et al. characterized MDSCs in lung transplant recipients to assess if MDSCs can serve as a potential new research target in the field [69]. They observed that G-MDSCs obtained from LTR were functionally suppressive and showed a modest correlation with increasing CNI trough levels, a previously reported phenomenon [70,71]. Previous studies demonstrated that expression of FK binding protein FKBP in Mo-MDSCs and PMN- MDSCs from tumor-bearing mice is increased and regulates their suppressive function [72]. Altogether these results indicate that MDSC activity and numbers are modulated by immunossupressive treatments, such as CNI. In contrast, MDSC percentages in our study were not related to immunosuppressant levels in peripheral blood. As our cohort of LTR was under the same immunosuppressive regimen, potential differences between treatments, with respect to their effect on MDSC frequency or function cannot be determined which still remains a limitation. In contrast with previous reports $[23,24]$ we observed that 90 and 180 days post-transplant Mo-MDSCs percentages were higher in patients who reject compared to those who do not reject.

\section{Heart, Corneal, Pancreatic islets and Skin Transplantation}

Ling Zhou, et al. found a cardioprotective role of MDSCs in heart failure [73] although the human MDSC response in heart transplantation remains unstudied. In murine models, several studies demonstrated MDSC were required for the induction of transplantation tolerance $[47,74,75]$. Some authors reported the development of MDSC and induction of tolerance after treating recipients with rapamycin and costimulatory blockade with anti-CD40L mAb [76,77] in contrast to mice treated with either rapamycin or anti-CD40L mAb alone [77]. Nakamura $\mathrm{T}$, et al. further observed that rapamycin increased PD-L1 expression on MDSC that accumulate in the cardiac allograft [78]. The effect of dexamethasone for the induction of MDSC was also reported [79] by Zhao, et al. In corneal allograft animal models it was observed an increase in allograft survival after MDSC infusion [80]. These data suggest that transplantation may lead to recipient derived MDSCs able to suppress anti-donor responses [81]. Further, it was observed an expansion of Mo-MDSC after dexamethasone administration [82] and rapamycin nano-micelle (RNM) ophthalmic solution treatment delayed rejection and expanded MDSC in allografts [83]. In pancreatic Islet transplantation MDSC infusion prolonged allograft survival and increased the number of Tregs within the graft $[84,85]$. MDSC generated by hepatic stellate cells (HCS) increased islets allograft survival [84]. As well as heart, corneal and pancreatic islet transplantation there is a lack of studies regarding skin human transplantation but several animal models pointed the ability of MDSC to increase skin graft 
survival [86,87]. Yang, et al. described that TNFa induced MDSC in vitro and the expression of iNOS was necessary for suppression of $\mathrm{T}$ cell proliferation [88]. The role of iNOS in MDSC function was also described by $\mathrm{Wu}$, et al. [89]. Liao, et al. reported induced iNOS expression and NO production in MDSC after dexamethasone treatment [90]. Rapamycin downregulates iNOS expression in MDSC, and the suppressive activity and MDSC numbers are significantly reduced after rapamycin treatment in an allogeneic skin transplant model [91]. The results confirm the administration of glucocorticoids as a therapeutic approach by increasing the development of MDSC and point $\mathrm{mTOR}$ as an intrinsic factor essential for the differentiation and immunosuppressive function of MDSCs.

\section{Conclusions and future directions}

MDSC are a group of immunoregulatory myeloid cells that are gaining attention throughout the years in the field of transplantation. Several animal models have point them as important regulators in transplantation but in human transplantation their role as a biomarkers and their potential use as immunotherapy to promote tolerance remains under investigation.

A major challenge in immune monitoring of transplant recipients is distinguishing between biomarkers changes as a consequence of underlying alloimmune responses from those related to immunosuppressive therapy. Conventional phenotyping of human Mo-MDSC subsets relies upon HLA-DR expression [17]. Although it may be possible MDSC increase naturally after transplantation [15] provided evidence supports that HLA-DR expression is influenced by standard immunosuppression, especially glucocorticoids $[33,34,37,56]$ which supports the need for new and specific markers to identify human MDSC. Then one of the more important goals for future studies is to define specific cell-surface markers and gating strategies that uniquely identify MDSC subpopulations [24]. The lack of specific markers also obliges to perform functional assays to check human MDSC function. In addition functional assays are difficult to implement due to their technical complexity and high intra-assay variability. In this regard, both the definition of specific markers and identification of the transcriptomic profile of human MDSC may shed light on the field [92]. Even though there are some studies regarding the effect of immunsuppressive drugs on human MDSC function, the effect of the current main immunosuppressive regiments on MDSCs should be further studied.

MDSC represent a promising therapeutic approach in solid organ transplantation but additional investigations are needed to fully understand their role in tolerance and to achieve immunosuppression withdrawal or minimization.

\section{Funding}

This work was partially granted by Instituto de Salud Carlos III (ISCIII COV20-0170).

\section{References}

1. Annual Data Report of the US Organ Procurement and Transplantation Network (2014) American journal of transplantation: official journal of the American Society of Transplantation and the American Society of Transplant Surgeons.

2. Ojo AO, Morales JM, González--Molina M, Steffick DE, Luan FL, et al. (2013) Comparison of the long--term outcomes of kidney transplantation: USA versus Spain. Nephrol Dial Transplant 28: 213-220. [Crossref]

3. Amodio G, Cichy J, Conde P, Matteoli G, Moreau A, et al. (2019) Role of myeloid regulatory cells (MRCs) in maintaining tissue homeostasis and promoting tolerance in autoimmunity, inflammatory disease and transplantation. Cancer Immunol Immunother 68:661-672. [Crossref]
4. Gabrilovich DI, Bronte V, Chen SH, Colombo MP, Ochoa A, et al. (2007) The terminology issue for myeloid--derived suppressor cells. Cancer Research 67: 1

5. Newby M, Wepsic HT (1986) Hematopoiesis and Suppressor Bone Marrow Cells in Mice Bearing Large Metastatic Lewis Lung Carcinoma Tumors. Cancer Res 47: 100105. [Crossref]

6. Buessow SC, Paul RD, Lopez DM (1984) Influence of mammary tumor progression on phenotype and function of spleen and in situ lymphocytes in mice. J Natl Cancer Inst 73: 249-255. [Crossref]

7. Seung LP, Rowley DA, Dubey P, Schreiber H (1995) Synergy between T--cell immunity and inhibition of paracrine stimulation causes tumor rejection. Proc Natl Acad Sci U S A 92: 6254-6258. [Crossref]

8. Hock BD, Mackenzie KA, Cross NB, Taylor KG, Currie MJ, et al. (2012) Renal transplant recipients have elevated frequencies of circulating myeloid--derived suppressor cells. Nephrol Dial Transplant 27: 402-410. [Crossref]

9. Jeong HJ, Lee HJ, Ko JH, Cho BJ, Park SY, et al. (2018) Myeloid--Derived Suppressor Cells Mediate Inflammation Resolution in Humans and Mice with Autoimmune Uveoretinitis. J Immunol 200: 1306-1315. [Crossref]

10. Dorhoi A, Du Plessis N (2018) Monocytic Myeloid--Derived Suppressor Cells in Chronic Infections. Front Immunol 8:1895. [Crossref]

11. Le Page A, Garneau H, Dupuis G, Frost EH, Larbi A, et al. (2017) Differential Phenotypes of Myeloid--Derived Suppressor and T Regulatory Cells and Cytokine Levels in Amnestic Mild Cognitive Impairment Subjects Compared to Mild Alzheimer Diseased Patients. Front Immunol 8: 783. [Crossref]

12. Hoechst B, Gamrekelashvili J, Manns MP, Greten TF, Korangy F (2011) Plasticity of human Th17 cells and iTregs is orchestrated by different subsets of myeloid cells. Blood 117: 6532-6541. [Crossref]

13. Millrud CR, Bergenfelz C, Leandersson K (2017) On the origin of myeloid--derived suppressor cells. Oncotarget 8: 3649-3665. [Crossref]

14. Zhang W, Li J, Qi G, Tu G, Yang C, et al. (2018) Myeloid--derived suppressor cells in transplantation: The dawn of cell therapy. J Transl Med 16: 19. [Crossref]

15. Scalea JR, Lee Y, Davila E, Bromberg JS (2019) Myeloid--Derived Suppressor Cells and their Potential Application in Transplantation. Transplantation 102: 359-367. [Crossref]

16. Huang B, Pan PY, Li Q, Sato AI, Levy DE, et al. (2006) Gr--1 + CD115 + Immature Myeloid Suppressor Cells Mediate the Development of Tumor--Induced T Regulatory Cells and T--Cell Anergy in Tumor--Bearing Host. Cancer Res 66: 1123-1131. [Crossref]

17. Bronte V, Brandau S, Chen SH, Colombo MP, Frey AB, et al. (2016) Recommendations for myeloid--derived suppressor cell nomenclature and characterization standards. Nat Commun 7: 12150. [Crossref]

18. Dumitru CA, Moses K, Trellakis S, Lang S, Brandau S (2012) Neutrophils and granulocytic myeloid-- derived suppressor cells: Immunophenotyping, cell biology and clinical relevance in human oncology. Cancer Immunol Immunother 61: 1155-1167. [Crossref]

19. Lang S, Bruderek K, Kaspar C, Höing B, Kanaan O, et al. (2018) Clinical relevance and suppressive capacity of human myeloid--derived suppressor cell subsets. Clin Cancer Res 24: 4834-4844. [Crossref]

20. Rodriguez PC, Ernstoff MS, Hernandez C, Atkins M, Zabaleta J, et al. (2009) Arginase I-- producing myeloid--derived suppressor cells in renal cell carcinoma are a subpopulation of activated granulocytes. Cancer Res 69: 1553-1560. [Crossref]

21. Mandruzzato S, Brandau S, Britten CM, Bronte V, Damuzzo V, et al. (2016) Toward harmonized phenotyping of human myeloid--derived suppressor cells by flow cytometry: results from an interim study. Cancer Immunol Immunother 65: 161-169. [Crossref]

22. Movahedi K, Guilliams M, Van Den Bossche J, Van Den Bergh R, Gysemans C, et al. (2008) Identification of discrete tumor--induced myeloid--derived suppressor cell subpopulations with distinct $\mathrm{T}$ cell suppressive activity. Blood 111: 4233-4244 [Crossref]

23. Youn JI, Collazo M, Shalova IN, Biswas SK, Gabrilovich DI (2012) Characterization of the nature of granulocytic myeloid--derived suppressor cells in tumor--bearing mice. J Leukoc Biol 91: 167-181. [Crossref]

24. Bruger AM, Dorhoi A, Esendagli G, Barczyk--Kahlert K, van der Bruggen P, et al. (2019) How to measure the immunosuppressive activity of MDSC: assays, problems and potential solutions. Cancer Immunol Immunother 68: 631-644. [Crossref] 
25. Bronte V, Wang M, Overwijk WW, Surman DR, Pericle F, et al. (1998) Apoptotic death of CD8+ T lymphocytes after immunization: induction of a suppressive population of Mac--1+/Gr--1+ cells. J Immunol 161: 5313-5320. [Crossref]

26. Chesney JA, Mitchell RA, Yaddanapudi K (2017) Myeloid--derived suppressor cells - a new therapeutic target to overcome resistance to cancer immunotherapy. $J$ Leukoc Biol 102: 727-740. [Crossref]

27. Green KA, Cook WJ, Green WR (2013) Myeloid--Derived Suppressor Cells in Murine Retrovirus--Induced AIDS Inhibit T-- and B--Cell Responses In Vitro That Are Used To Define the Immunodeficiency. J Virol 87(4). [Crossref]

28. Wang C, Zhang N, Qi L, Yuan J, Wang K, et al. (2017) Myeloid--Derived Suppressor Cells Inhibit T Follicular Helper Cell Immune Response in Japanese Encephalitis Virus Infection. J Immunol 199: 3094-3105. [Crossref]

29. Wang L, Cao D, Wang L, Zhao J, Nguyen LN, et al. (2018) HCV--associated exosomes promote myeloid--derived suppressor cell expansion via inhibiting miR--124 to regulate T follicular cell differentiation and function. Cell Discov 4: 51. [Crossref]

30. Poschke I, Mao Y, Adamson L, Salazar--Onfray F, Masucci G, et al. (2012) Myeloid-derived suppressor cells impair the quality of dendritic cell vaccines. Cancer Immunol Immunother 61: 827-838. [Crossref]

31. Rodríguez PC, Ochoa AC (2008) Arginine regulation by myeloid derived suppressor cells and tolerance in cancer: Mechanisms and therapeutic perspectives. Immunol Rev 222: 180-191. [Crossref]

32. Kumar V, Patel S, Tcyganov E, Gabrilovich DI (2016) The Nature of Myeloid-Derived Suppressor Cells in the Tumor Microenvironment. Trends Immunol 37: 208220. [Crossref]

33. Mintzer DM, Billet SN, Chmielewski L (2009) Drug--induced hematologic syndromes. Advances in Hematology pp: 1-11.

34. Varga G, Ehrchen J, Tsianakas A, Tenbrock K, Rattenholl A, et al. (2008) Glucocorticoids induce an activated, anti--inflammatory monocyte subset in mice that resembles myeloid-- derived suppressor cells. J Leukoc Biol 84: 644-650. [Crossref]

35. Ehrchen J, Steinmüller L, Barczyk K, Tenbrock K, Nacken W, et al. (2007) Glucocorticoids induce differentiation of a specifically activated, anti--inflammatory subtype of human monocytes. Blood 109: 1265-1274. [Crossref]

36. Tulzo Y Le, Pangault C, Amiot L, Guilloux V, Tribut O, et al. (2004) Monocyte human leukocyte antigen--DR transcriptional downregulation by cortisol during septic shock. Am J Respir Crit Care Med 169: 1144-1151. [Crossref]

37. Volk T, Schmutzler M, Engelhardt L, Döcke WD, Volk HD, et al. (2001) Influence of aminosteroid and glucocorticoid treatment on inflammation and immune function during cardiopulmonary bypass. Crit Care Med 29: 2137-2142. [Crossref]

38. Dugast AS, Haudebourg T, Coulon F, Heslan M, Haspot F, et al. (2008) Myeloid-Derived Suppressor Cells Accumulate in Kidney Allograft Tolerance and Specifically Suppress Effector T Cell Expansion. J Immunol 180: 7898-7906. [Crossref]

39. Mazzoni A, Bronte V, Visintin A, Spitzer JH, Apolloni E, et al. (2002) Myeloid Suppressor Lines Inhibit T Cell Responses by an NO--Dependent Mechanism. $J$ Immunol 168: 689-695. [Crossref]

40. Dilek N, de Silly RV, Blancho G, Vanhove B (2012) Myeloid--derived suppressor cells: Mechanisms of action and recent advances in their role in transplant tolerance. Front Immunol 3: 208. [Crossref]

41. Dilek N, Poirier N, Usal C, Martinet B, Blancho G, et al. (2012) Control of Transplant Tolerance and Intragraft Regulatory $\mathrm{T}$ Cell Localization by Myeloid--Derived Suppressor Cells and CCL5. J Immunol 188: 4209-4216. [Crossref]

42. Luan Y, Mosheir E, Menon MC, Wilson D, Woytovich C, et al. (2013) Monocytic Myeloid-- Derived Suppressor Cells Accumulate in Renal Transplant Patients and Mediate CD4 + Foxp3 + Treg Expansion. Am J Transplant 13: 3123-3131. [Crossref]

43. Utrero-Rico A, Laguna-Goya R, Cano-Romero F, Chivite-Lacaba M, GonzalezCuadrado C, et al. (2020) Early Posttransplant Mobilization of M--MDSC Correlates with Increase in Soluble Immunosuppressive Factors and Predicts Cancer in Kidney Recipients. Transplantation 104: 2599-2608. [Crossref]

44. Hock BD, McKenzie JL, Cross NB, Currie MJ (2015) Dynamic changes in myeloid derived suppressor cell subsets following renal transplant: A prospective study. Transpl Immunol 32: 164-171. [Crossref]

45. Iglesias-Escudero M, Sansegundo-Arribas D, Riquelme $\mathrm{P}$, Merino-Fernández D, Guiral-Foz S, et al. (2020) Myeloid--Derived Suppressor Cells in Kidney Transplan Recipients and the Effect of Maintenance Immunotherapy. Front Immunol 11: 643. [Crossref]
46. Du XX, Guo YL, Zhao YP, Yang M, Chang S, et al. (2018) Accumulation of High Levels of Monocytic Myeloid--Derived Suppressor Cells Enhances Graft Survival in Almost--Tolerant Kidney Transplant Recipients. Transplant Proc 50: 3314-3320. [Crossref]

47. Garcia MR, Ledgerwood L, Yang Y, Xu J, Lal G, et al. (2010) Monocytic suppressive cells mediate cardiovascular transplantation tolerance in mice. J Clin Invest 120: 24862496. [Crossref]

48. Meng F, Chen S, Guo X, Chen Z, Huang X, et al. (2014) Clinical Significance of Myeloid--Derived Suppressor Cells in Human Renal Transplantation with Acute T Cell--Mediated Rejection. Inflammation 37: 1799-1805. [Crossref]

49. Rekers NV, Bajema IM, Mallat MJK, Petersen B, Anholts JDH, et al. (2016) Beneficial Immune Effects of Myeloid--Related Proteins in Kidney Transplant Rejection. Am J Transplant 16: 1441-1455. [Crossref]

50. Zhang C, Wang S, Li J, Zhang W, Zheng L, et al. (2017) The mTOR signal regulates myeloid-- derived suppressor cells differentiation and immunosuppressive function in acute kidney injury. Cell Death Dis 8: e2695. [Crossref]

51. Braza MS, van Leent MMT, Lameijer M, Sanchez--Gaytan BL, Arts RJW, et al. (2018) Inhibiting Inflammation with Myeloid Cell--Specific Nanobiologics Promotes Organ Transplant Acceptance. Immunity 49: 819-828. [Crossref]

52. Ochando J, Fayad ZA, Madsen JC, Netea MG, Mulder WJM (2020) Trained immunity in organ transplantation. Am J Transplant 20: 10-18. [Crossref]

53. Mulder WJM, Ochando J, Joosten LAB, Fayad ZA, Netea MG (2019) Therapeutic targeting of trained immunity. Nat Rev Drug Discov 18: 553-566. [Crossref]

54. Moon JS, Hisata S, Park MA, DeNicola GM, Ryter SW, et al. (2015) MTORC1Induced HK1-- Dependent Glycolysis Regulates NLRP3 Inflammasome Activation. Cell Rep 12: 102-115. [Crossref]

55. Settmacher U, Docke WD, Manger T, Fietze E, Ruckert R, et al. (1993) Management of induction phase of immunosuppression in liver graft recipients: Prevention of oversuppression by immune monitoring. Transplant Proc 25: 2703-2704. [Crossref]

56. Haveman JW, Van Den Berg AP, Van Den Berk JMM, Mesander G, Slooff MJH, et al. (1999) Low HLA--DR expression on peripheral blood monocytes predicts bacterial sepsis after liver transplantation: Relation with prednisolone intake. Transpl Infect Dis 1: 146-152. [Crossref]

57. Weston CJ, Zimmermann HW, Adams DH (2019) The role of myeloid--derived cells in the progression of liver disease. Front Immunol 10: 893. [Crossref]

58. Chou HS, Hsieh CC, Yang HR, Wang L, Arakawa Y, et al. (2011) Hepatic stellate cells regulate immune response by way of induction of myeloid suppressor cells in mice. Hepatology 53: 1007-1019. [Crossref]

59. Bernsmeier C, Triantafyllou E, Brenig R, Lebosse FJ, Singanayagam A, et al. (2018) CD14+ CD15- HLA--DR- myeloid--derived suppressor cells impair antimicrobial responses in patients with acute--on--chronic liver failure. Gut 67: 1155-1167. [Crossref]

60. Zhang Y, Bi Y, Yang H, Chen X, Liu H, et al. (2014) mTOR limits the recruitment of CD11b + Gr1 + Ly6C high myeloid--derived suppressor cells in protecting against murine immunological hepatic injury. J Leukoc Biol 95: 961-970. [Crossref]

61. Hamdani S, Thiolat A, Naserian S, Grondin C, Moutereau S, et al. (2017) Delayed and short course of rapamycin prevents organ rejection after allogeneic liver transplantation in rats. World J Gastroenterol 23: 6962-6972. [Crossref]

62. Hoffman JA, Weinberg KI, Azen CG, Horn M V, Dukes L, et al. (2004) Human leukocyte antigen--DR expression on peripheral blood monocytes and the risk of pneumonia in pediatric lung transplant recipients. Transpl Infect Dis 6: 147-155. [Crossref]

63. Alingrin J, Coiffard B, Textoris J, Nicolino--Brunet C, Gossez M, et al. (2018) Sepsis is associated with lack of monocyte HLA--DR expression recovery without modulating T--cell reconstitution after lung transplantation. Transpl Immunol 51: 6-11. [Crossref]

64. Deshane JS, Redden DT, Zeng M, Spell ML, Zmijewski JW, et al. (2015) Subsets of airway myeloid--derived regulatory cells distinguish mild asthma from chronic obstructive pulmonary disease. J Allergy Clin Immunol 135: 413-424.e15. [Crossref]

65. Scrimini S, Pons J, Agustí A, Soriano JB, Cosio BG, et al. (2013) Differential effects of smoking and COPD upon circulating myeloid derived suppressor cells. Respir Med 107: 1895-1903. [Crossref]

66. Lebrun A, Lo Re S, Chantry M, Izquierdo Carerra X, Uwambayinema F, et al. (2017) CCR2+ monocytic myeloid--derived suppressor cells (M--MDSCs) inhibit collagen degradation and promote lung fibrosis by producing transforming growth factor-- $\beta 1 . J$ Pathol 243: 320-330. [Crossref] 
67. Yeager ME, Nguyen CM, Belchenko DD, Colvin KL, Takatsuki S, et al. (2012) Circulating myeloid-- derived suppressor cells are increased and activated in pulmonary hypertension. Chest 141: 944-952. [Crossref]

68. Sharma NS, Wille KM, Athira S, Zhi D, Hough KP, et al. (2018) Distal airway microbiome is associated with immunoregulatory myeloid cell responses in lung transplant recipients. J Hear Lung Transplant 37: 17: 31898-31903. [Crossref]

69. Heigl T, Singh A, Saez-Gimenez B, Kaes J, Van Herck A, et al. (2019) Myeloid-derived suppressor cells in lung transplantation. Front Immunol 10: 900. [Crossref]

70. Han C, Wu T, Na N, Zhao Y, Li W, et al. (2016) The effect of immunosuppressive drug cyclosporine A on myeloid--derived suppressor cells in transplanted mice. Inflamm Res 65: 679-688. [Crossref]

71. Yang F, Li Y, Zhang Q, Tan L, Peng L, et al. (2018) The Effect of Immunosuppressive Drugs on MDSCs in Transplantation. J Immunol Res 2018: 5414808. [Crossref]

72. Kim YS, Kim YJ, Lee JM, Kim EK, Park YJ, et al. (2012) Functional Changes in Myeloid-- Derived Suppressor Cells (MDSCs) during Tumor Growth: FKBP51 Contributes to the Regulation of the Immunosuppressive Function of MDSCs. $J$ Immunol 188: 4226-4234. [Crossref]

73. Zhou L, Miao K, Yin B, Li H, Fan J, et al. (2018) Cardioprotective role of myeloidderived suppressor cells in heart failure. Circulation 138: 181-197. [Crossref]

74. Cai S, Choi JY, Borges TJ, Zhang H, Miao J, et al. (2020) Donor myeloid derived suppressor cells (MDSCs) prolong allogeneic cardiac graft survival through programming of recipient myeloid cells in vivo. Sci Rep 10: 14249. [Crossref]

75. Lee YS, Zhang T, Saxena V, Li L, Piao W, et al. (2020) Myeloid--derived suppressor cells expand after transplantation and their augmentation increases graft survival. Am J Transplant 20: 2343-2355. [Crossref]

76. Gong W, Ge F, Liu D, Wu Y, Liu F, et al. (2014) Role of myeloid--derived suppressor cells in mouse pre--sensitized cardiac transplant model. Clin Immunol 153: 8-16. [Crossref]

77. Nakamura T, Nakao T, Yoshimura N, Ashihara E (2015) Rapamycin Prolongs Cardiac Allograft Survival in a Mouse Model by Inducing Myeloid--Derived Suppressor Cells. Am J Transplant 15: 2364-2377. [Crossref]

78. Nakamura T, Nakao T, Ashihara E, Yoshimura N (2016) Myeloid--derived Suppressor Cells Recruit CD4+/Foxp3+ Regulatory $\mathrm{T}$ Cells in a Murine Cardiac Allograft. Transplant Proc 48: 1275-1278. [Crossref]

79. Zhao Y, Shen XF, Cao K, Ding J, Kang X, et al. (2018) Dexamethasone--induced myeloid--derived suppressor cells prolong allo cardiac graft survival through iNOSand glucocorticoid receptor-- dependent mechanism. Front Immunol 9: 282 [Crossref]

80. Guillonneau C (2015) Efficacy of myeloid derived suppressor cells on transplant survival. Vol. 99, Transplantation 99: 2017-2019. [Crossref]
81. He Y, Wang B, Jia B, Guan J, Zeng H, et al. (2015) Effects of adoptive transferring different sources of myeloid--derived suppressor cells in mice corneal transplant survival. Transplantation 99: 2102-2108. [Crossref]

82. Lee HJ, Park SY, Jeong HJ, Kim HJ, Kim MK, et al. (2018) Glucocorticoids induce corneal allograft tolerance through expansion of monocytic myeloid--derived suppressor cells. Am J Transplant 18: 3029-3037. [Crossref]

83. Wei C, Wang Y, Ma L, Wang X, Chi H, et al. (2018) Rapamycin nano--micelle ophthalmic solution reduces corneal allograft rejection by potentiating myeloid-derived suppressor cells' function. Front Immunol 9: 2283. [Crossref]

84. Qin J, Arakawa Y, Morita M, Fung JJ, Qian S, et al. (2017) Chemokine Receptor Type 2--Dependent Migration of Myeloid--Derived Suppressor Cells in Protection of Islet Transplants. Transplantation 101: 1793-1800. [Crossref]

85. Marigo I, Bosio E, Solito S, Mesa C, Fernandez A, et al. (2010) Supplemental Information Tumor--Induced Tolerance and Immune Suppression Depend on the C / EBP $\beta$ Transcription Factor. Immunity 32: 790-802. [Crossref]

86. Carretero-Iglesia L, Bouchet-Delbos L, Louvet C, Drujont L, Segovia M, et al (2016) Comparative Study of the Immunoregulatory Capacity of in Vitro Generated Tolerogenic Dendritic Cells, Suppressor Macrophages, and Myeloid--Derived Suppressor Cells. Transplantation 100: 2079-2089. [Crossref]

87. Drujont L, Carretero-Iglesia L, Bouchet-Delbos L, Beriou G, Merieau E, et al. (2014) Evaluation of the therapeutic potential of bone Marrow--Derived Myeloid Suppressor Cell (MDSC) adoptive transfer in mouse models of autoimmunity and allograft rejection. PLoS One 9: e100013. [Crossref]

88. Yang F, Li Y, Wu T, Na N, Zhao Y, et al. (2016) TNF $\alpha$--induced M--MDSCs promote transplant immune tolerance via nitric oxide. J Mol Med 94: 911-920. [Crossref]

89. Wu T, Sun C, Chen Z, Zhen Y, Peng J, et al. (2012) Smad3--Deficient CD11b + Gr1 + Myeloid--Derived Suppressor Cells Prevent Allograft Rejection via the Nitric Oxide Pathway. J Immunol 189: 4989-5000. [Crossref]

90. Liao J, Wang X, Bi Y, Shen B, Shao K, et al. (2014) Dexamethasone potentiates myeloid--derived suppressor cell function in prolonging allograft survival through nitric oxide. J Leukoc Biol 96: 675-684. [Crossref]

91. Wu T, Zhao Y, Wang H, Li Y, Shao L, et al. (2016) MTOR masters monocytic myeloid--derived suppressor cells in mice with allografts or tumors. Sci Rep 6: 20250. [Crossref]

92. Fridlender ZG, Sun J, Mishalian I, Singhal S, Cheng G, et al. (2012) Transcriptomic analysis comparing tumor--associated neutrophils with granulocytic myeloid--derived suppressor cells and normal neutrophils. PLoS One 7: e31524. [Crossref]

Copyright: (C2021 Escudero MI. This is an open-access article distributed under the terms of the Creative Commons Attribution License, which permits unrestricted use, distribution, and reproduction in any medium, provided the original author and source are credited. 